\title{
DETERMINACIÓN DE LA SEROPREVALENCIA \\ DE ANTICUERPOS PARA Brucella abortus EN \\ TRABAJADORES DE UN FRIGORÍFICO Y ORDEÑADORES EN MONTERÍA, CÓRDOBA (COLOMBIA)
}

\section{DETERMINATION OF ANTIBODIES SEROPREVALENCE TO Brucella abortus IN SLAUGTHERHOUSE WORKERS AND MILKERS IN MONTERÍA, CÓRDOBA (COLOMBIA)}

\author{
Gustavo Quintero ${ }^{1}$, Alfonso Calderón ${ }^{2}$, Virginia Rodríguez ${ }^{3}$, Cindy Barrios ${ }^{4}$, María Fernanda Yasnot $^{5}$, Marilyn Villadiego $^{6}$
}

\begin{abstract}
${ }^{1}$ M.V., M.Sc. Docente. Grupo de Investigaciones Microbiológicas y Biomédicas de Córdoba (GIMBIC), Programa de Bacteriología, Facultad Ciencias de la Salud, Universidad de Córdoba, Montería-Córdoba, Colombia, e-mail: gustavoquintero@ correo.unicordoba.edu.co; ${ }^{2}$ M.V.Z., M.Sc. Docente. Instituto de Investigaciones Biológicas del Trópico (IIBT), Facultad de Medicina Veterinaria Zootecnia, Universidad de Córdoba. Montería-Córdoba, Colombia, e-mail: acalderonr@correo.unicordoba. edu.co; ${ }^{3}$ Bacterióloga, M.Sc. Docente. Grupo de Investigaciones Microbiológicas y Biomédicas de Córdoba (GIMBIC), Programa de Bacteriología, Facultad de Ciencias de la Salud, Universidad de Córdoba, e-mail: vrodriguez@correo.unicordoba. edu.co; ${ }^{4}$ Bacterióloga. Universidad de Córdoba, Facultad Ciencias de la Salud, e-mail: nova0904@hotmail.com; ${ }^{5}$ Bacterióloga Ph.D. Docente. Grupo de Investigaciones Microbiológicas y Biomédicas de Córdoba (GIMBIC), Facultad Ciencias de la Salud, Universidad de Córdoba, Programa de Bacteriología, Universidad de Córdoba, e-mail: myasnot@correo.unicordoba. edu.co; ${ }^{6}$ Enfermera. Ph.D. Programa de Bacteriología, Facultad Ciencias de la Salud, Universidad de Córdoba, e-mail: mvilladiego@correo.unicordoba.edu.co
\end{abstract}

Rev. U.D.C.A Act. \& Div. Cient. 17(2): 333-340, Julio-Diciembre, 2014

\section{RESUMEN}

La brucelosis es una zoonosis bacteriana, considerada enfermedad profesional, de muy alto impacto socio-económico, con más de 500.000 casos nuevos cada año en todo el mundo y, de la cual, en Colombia hay muy pocos estudios, aislados temporal y geográficamente. La población en riesgo, la constituyen los trabajadores de frigoríficos, ordeñadores, veterinarios y bacteriólogos. Tradicionalmente, el diagnóstico se ha realizado por Rosa de Bengala y confirmado por ELISA competitivo o por aislamiento del patógeno. El propósito de este estudio fue la detección de anticuerpos contra Brucella abortus en trabajadores de un frigorífico y ordeñadores, en Montería, Córdoba (Colombia) y, adicionalmente, se compararon los dos métodos convencionales con el de Polarización de la Fluorescencia. Se tomaron muestras de sangre sin anticoagular, a 162 trabajadores y se procesaron, en busca de anticuerpos contra $B$. abortus con Rosa de Bengala, ELISA competitivo y dos protocolos de Polarización de la Fluorescencia. Se aplicó una encuesta para determinar el grado de conocimiento y actitudes que tienen los voluntarios con respecto al problema. Se encontró que el 7,41\% de las muestras fueron positivas, por Rosa de Bengala, el 2,8\%, con el protocolo 1 y, el 15,33\%, con el protocolo 2 de Polarización fluorescente. Las muestras que fueron positivas con cualquiera de los dos métodos, se confirmaron por ELISA competitivo, método con el que se encontró una seroprevalencia del $0,7 \%$. En esta población, se presenta una baja seroprevalencia de anticuerpos de $B$. abortus; el $50,81 \%$ del frigorífico y el $47,11 \%$ de las fincas, conocen la enfermedad y asumen actitudes para evitar su contagio.

Palabras clave: Brucella abortus, seroprevalencia, salud ocupacional, zoonosis.

\section{SUMMARY}

Brucellosis is a bacterial zoonosis, considered an occupational disease that has high socioeconomic impact, with more than 500,000 new cases each year worldwide. In Colombia there are very few studies, temporally and geographically isolated. The population at risk are salaugtherhouse's workers, milkers, veterinarians and bacteriologists. Traditionally, the diagnosis has been made by Rose Bengal and confirmed by competitive ELISA or pathogen isolation. The purpose of this study was the detection of antibodies to Brucella abortus in 
slaughterhouse's workers and milkers in Monteria, Cordoba (Colombia) and, additionally, the two conventional methods were compared with Fluorescence Polarization. Blood samples were taken without anticoagulation from 162 workers and processed for antibodies against $B$. abortus with Rose Bengal, competitive ELISA and two Fluorescence Polarization protocols. A survey to determine the level of knowledge and attitudes that have volunteers about the problem was implemented. It was found that $7.41 \%$ of the samples were positive by Rose Bengal, $2.8 \%$ with protocol 1 and $15.33 \%$ with protocol 2 of fluorescence polarization. The samples that were positive with either method were confirmed by competitive ELISA. A seroprevalence of $0.7 \%$ was found. In this population there is a low seroprevalence of antibodies to $B$. abortus; $50.81 \%$ of the slaughterhouse workers and $47.11 \%$ of the farms workers, know the disease and assume attitudes to prevent contagion.

Key words: Brucella abortus, seroprevalence, occupational health, zoonoses.

\section{INTRODUCCIÓN}

La brucelosis es uno de los más importantes problemas de salud, tanto humana como animal. Además del efecto contra la salud, produce un enorme impacto económico, representado en pérdida de animales, tratamientos costosos y prolongados, periodos reproductivos fallidos e incapacidades laborales, en los humanos afectados (Obradović \& Velić, 2010; Dean et al. 2012). La enfermedad se transmite a los humanos por consumo de alimentos contaminados o por contacto directo con animales infectados (Fernández \& Gómez, 2009) y provoca, anualmente, más de 500.000 nuevos casos con incidencias, entre menos de dos y más de 500 por cada 100.000 habitantes (Ciochini et al. 2013).

Desde el punto de vista de la salud humana, de las especies existentes, Brucella melitensis, $B$. suis, $B$. abortus y $B$. canis son las más importantes (Olivera et al. 2013). La brucelosis humana es una enfermedad febril inespecífica, sin signos característicos, que puede afectar sistemas multiorgánicos y causar complicaciones debilitantes (Nökler et al. 2009). Los síntomas incluyen fiebre ondulante, dolor de cabeza, sudoraciones nocturnas, dolor muscular y articular, hepatomegalia y esplenomegalia (Obradović \& Velić, 2010).

El principal impacto de la brucelosis es la pérdida de la habilidad reproductiva de los animales y la disminución de la productividad laboral de los humanos (Morales \& Combariza, 2004; Halling et al. 2005). Ocasiona grandes costos a la economía, en términos de pruebas médicas, de tratamientos y ausentismo laboral, convirtiéndola, además, en un problema social, afectando también el turismo y el comercio; igualmente, Brucella sp. es considerada agente biológico para el terrorismo (Obradović \& Velić, 2010).
El tamizaje y el diagnóstico de esta enfermedad, se realiza mediante múltiples pruebas; de su confiabilidad y rapidez depende el inicio de una terapia adecuada (Lucero et al. 2008).

Como los signos y los síntomas de la brucelosis no son patognomónicos, el diagnóstico clínico debe ser hecho siempre por pruebas bacteriológicas o serológicas. Esto no siempre es posible y, entonces, se realizan pruebas indirectas basadas en la identificación de anticuerpos específicos contra los antígenos de Brucella (Clavijo et al. 2003).

El cultivo de Brucella spp. constituye el método diagnóstico definitivo, considerado como el estándar de oro (Ciochini et al. 2013), que se suele obtener por hemocultivo, por el medio clásico de Ruiz Castañeda (Castro et al. 2005) o cultivo de médula ósea y, más raramente, por cultivo de líquido cefalorraquídeo, líquido articular o exudado purulento (Wellinghausen et al. 2006). El porcentaje de casos positivos basados en el cultivo oscila entre 15 y $70 \%$ (Pappas et al. 2005).

El método diagnóstico más antiguo y aún empleado es la prueba de aglutinación con Rosa de Bengala (RB), que emplea como antígeno una suspensión de células de Brucella abortus (B. abortus), cepa 1119-3 o 99S, en fase lisa, recomendadas por los organismos internacionales de referencia, para la elaboración de antígenos, tanto para uso humano como para animales (OIE, 2008). Proporcionan una aproximación diagnóstica en pocos minutos con una sensibilidad y especificidad del 100 y 97\%, respectivamente (Díaz et al. 2011).

También existen métodos moleculares, como el de Reacción en Cadena de la Polimerasa (PCR por sus siglas en inglés), que es otra forma para poner de manifiesto a Brucella spp. en la sangre, Líquido Cefalorraquídeo (LCR) y otras muestras (OIE, 2008). La ventaja que presenta es su rapidez, sensibilidad, especificidad y, además, permite identificar el ADN libre y procedente de bacterias muertas o dañadas por el sistema inmune o los antibióticos; sin embargo, se necesita de entrenamiento especializado y es costoso (Mitka et al. 2007).

Actualmente, se utilizan las llamadas pruebas de captura primaria, las que comprenden la Competitive Enzyme-Linked Immunosorbent Assay (C-Elisa) y la prueba de polarización de la fluorescencia (FPA), que están en el ápice del desarrollo actual (Nielsen et al. 2004; Rojas et al. 2004). En el caso de la FPA, por su alta sensibilidad (entre 98,1 y 99,02\%) y especificidad (entre 99,8 y 100\%), además de su rapidez, no más de 5 minutos por prueba y movilidad, ya que puede ser ejecutada por fuera del laboratorio de diagnóstico, utilizando un analizador portátil (Nielsen et al. 1996); esta prueba mide el grado de polarización de la luz emitida por moléculas fluorescentes. En la FPA para el diagnóstico de brucelosis, un 
antígeno específico de $B$. abortus (fracción O-LPS de una cepa en fase lisa de $B$. abortus), se marca con fluoresceína (conjugado); al añadir el conjugado a una muestra que contiene anticuerpos específicos de Brucella (muestra positiva), se forma un inmunocomplejo de masa elevada. Este complejo es voluminoso y presenta una rotación lenta, por lo que despolariza la luz, sólo de modo parcial. Si no hay presentes anticuerpos específicos de Brucella (muestra negativa), el conjugado queda sin ligarse; este conjugado de menor tamaño presenta una rotación más rápida, lo que aumenta la despolarización (Nielsen \& Yu, 2010).

El propósito de este estudio fue la detección de anticuerpos contra Brucella abortus en trabajadores de un frigorífico y ordeñadores en Montería y determinar del grado de comprensión que tienen ellos del problema que representa esta zoonosis. Además, comparar los dos métodos convencionales (RB y C-ELISA) con la técnica de FPA. Este estudio permitió un acercamiento al conocimiento del estado actual de la transmisión de Brucella abortus. a humanos en riesgo, en Montería y se espera que sirva para la implementación de nuevos programas de promoción y prevención, dirigidos a las personas directamente involucradas en el trabajo con animales, susceptibles o sus productos.

\section{MATERIALES Y MÉTODOS}

Tipo de estudio. Se realizó un estudio descriptivo de corte transversal.

Zona de estudio. El presente estudio, se adelantó en un frigorífico y en 8 fincas del municipio de Montería, situado a $8^{\circ} 45^{\prime} 27^{\prime \prime}$ de latitud norte y $75^{\circ} 53^{\prime} 24^{\prime \prime}$ al oeste de Greenwich, con un área aproximada de $3.142 \mathrm{~km}^{2}$; la temperatura promedio anual es de $28^{\circ} \mathrm{C}$, con picos mínimos de $16^{\circ} \mathrm{C}$ y máximos de $35^{\circ} \mathrm{C}$, en época de lluvias y de $22^{\circ} \mathrm{C}$ a $45^{\circ} \mathrm{C}$, en temporada seca. La humedad relativa promedio anual es de 85\% (Pulido et al. 2002).

Población de estudio. Por conveniencia, se contactaron 162 trabajadores: 99, de un frigorífico y 63, ordeñadores de 8 fincas, seleccionadas de entre todas los predios del municipio de Montería y que tuvieran sistema de explotación de doble propósito, que hubieran tenido bovinos con diagnóstico de brucelosis en los dos últimos años, que permitieron el acceso a la toma de muestras a los trabajadores y que aceptaran participar en el estudio, por medio de la firma de un consentimiento informado. Todos los voluntarios fueron adultos, de ambos géneros, entre 2 y 216 meses de trabajo en su ocupación, en el momento de tomar las muestras.

Toma de muestras. A cada uno de los participantes, se le tomaron $5 \mathrm{~mL}$ de sangre sin anticoagulante, en tubo vacutainer (Becton Dickinson ${ }^{\circledR}$ ), marcados con el nombre y la fe- cha; las muestras, se mantuvieron refrigeradas hasta el momento de su procesamiento y fueron llevadas al laboratorio del Grupo de Investigaciones Microbiológicas y Biomédicas de Córdoba, GIMBIC, en el Programa de Bacteriología de la Facultad Ciencias de la Salud, de la Universidad de Córdoba. El suero fue separado, alicuotado en crioviales de $0,5 \mathrm{~mL}$ y preservado a $-20^{\circ} \mathrm{C}$, hasta su utilización.

Diagnóstico por RB. Esta técnica, se basa en la aglutinación de los complejos inmunes que se forman al reaccionar los anticuerpos del suero que se está analizando con el antígeno de $B$. abortus S99, tamponado a pH 3,65 y teñido con el colorante RB (Institute Pourquier, Montpellier, France). De cada una de las 162 muestras, se tomaron, sin diluciones, $30 \mu \mathrm{l}$ de suero, en una placa de vidrio y se adicionaron $30 \mu \mathrm{L}$ de reactivo de RB; se mezclaron suavemente y se dejaron reaccionar por 4 minutos en movimiento continuo, en un agitador orbital y se consideraron como positivas, las muestras en las que, al examinarlas en el aglutinoscopio, se observó aglutinación y, negativas, aquellas que no la tuvieron.

Diagnóstico por FPA. Se probaron dos protocolos diferentes: FPA-1 y FPA-2. El primero, diseñado para el diagnóstico en muestras de animales y, el segundo, para el diagnóstico en muestras en humanos. El procedimiento fue similar $y$, las diferencias, se remiten a las cantidades relativas de reactivos: para FPA-1, $1 \mathrm{~mL}$ de buffer; $10 \mu \mathrm{L}$, de suero y, $10 \mu \mathrm{L}$, de antígeno, mientras que para la FPA-2, se usaron: $2 \mathrm{~mL}$, de buffer; $40 \mu \mathrm{L}$, de suero y, $20 \mu \mathrm{L}$, de antígeno. Los dos protocolos, se realizaron con el kit para FPA de Diachemix LTD y leídos en el equipo lector de polarización Sentry $100^{\circledR}$. Con el primer método, se probaron 143 sueros, que se procesaron de acuerdo con las instrucciones del proveedor.

El control negativo (componente 2 del kit comercial), se procesó de la siguiente forma: con los reactivos a temperatura ambiente, en un tubo de borosilicato, se puso $1 \mathrm{~mL}$ de buffer diluido y se agregaron $10 \mu \mathrm{L}$ del control negativo; se agitó en el vórtex, se dejó incubar a temperatura ambiente durante 5 minutos y se midió la polarización (esta lectura quedó registrada como blanco). Se añadieron, luego, $10 \mu \mathrm{L}$ del antígeno conjugado, se mezcló en el vórtex, se dejó a temperatura ambiente por lo menos por 2 minutos y, posteriormente, se midió la intensidad en el equipo. Esta lectura, se repitió dos veces más y el promedio de las lecturas quedó registrado como valor del control negativo.

Para el control positivo (componente 1 del kit comercial) y las muestras problema, se repitieron los pasos descritos, pero solamente se realizó una lectura, luego de la adición del conjugado; los resultados, se expresan en milipolarizaciones (mP). Se consideró que una muestra fue positiva si fue mayor de 94mP y, negativa, de 94 o menos; con el segundo método, FPA-2, se probaron 150 muestras. Los tiempos de incubación y el procedimiento para las lecturas fueron similares. 
Diagnóstico por C-ELISA. Se analizaron las muestras que habían sido positivas por una o más de las otras técnicas; en total, 145 muestras.

Está técnica, se implementó con el kit Brucella (BrucellaAb C-ELISA) Svanovir ${ }^{\circledR}$ (Boehringer Ingelheim. Uppsala, Sweden). Tanto los controles como las muestras, se corrieron por duplicado. En los pozos correspondientes, se pusieron $45 \mu \mathrm{L}$ de buffer y se adicionaron $5 \mu \mathrm{L}$ de controles (positivo, positivo débil y negativo) y sueros; seguidamente, se añadieron $50 \mu \mathrm{L}$ de solución de anticuerpos monoclonales en todos los pozos. La placa se selló, se puso en agitación durante 5 minutos y se incubó a $23^{\circ} \mathrm{C}$, por 30 minutos. Se lavó la placa 4 veces con solución bufferada twin-PBS; se adicionaron $100 \mu \mathrm{L}$ de conjugado en cada pozo y se hizo una nueva incubación por 30 minutos, a $23^{\circ} \mathrm{C}$; posteriormente, se lavó, de nuevo, con twin-PBS, se adicionaron $100 \mu \mathrm{L}$ del sustrato y contando desde el momento en que se puso el sustrato en el primer pozo, se contaron 10 minutos de incubación, a temperatura ambiente, $23^{\circ} \mathrm{C}$. La reacción, se detuvo con $50 \mu \mathrm{L}$ de solución de parada, mezclando fuertemente en cada pozo. La lectura de las densidades ópticas, se hizo a 450nm, en un lector de ELISA; para la interpretación de los resultados, se calculó el Porcentaje de Inhibición (PI), de acuerdo con la fórmula:

$$
\mathrm{PI}=\frac{\text { Promedio de DO (muestras /Ctrls.) x } 100}{\text { Promedio de DO Ctrl. de conjugado }}
$$

Las muestras fueron positivas, si el PI es $\geq 30 \%$ y, negativas, si PI es $<30 \%$.

Encuestas. Se aplicaron encuestas del tipo Conocimiento, Actitudes y Prácticas (CAP), con las que se preguntó sobre el conocimiento individual acerca de la brucelosis; síntomas como fiebres, artralgias, fatiga, sudoración, cefalea, lumbalgia y debilidad física; los diferentes aspectos sociodemográficos, laborales y de salud ocupacional.

Análisis estadístico. Los datos de las encuestas y de los diferentes diagnósticos implementados, se tabularon en una hoja electrónica; se realizó un análisis descriptivo de variables edad, sexo, ocupación y procedencia; también, se calculó el valor de Kappa, para el grado de asociación entre las diferentes pruebas diagnósticas; se utilizó el software SAS, para el análisis estadístico.

Aspectos éticos. Todas las activides del presente trabajo se realizaron de acuerdo con las normas éticas vigentes: Declaración de Helsinki y la Resolución 08430 de 1993, del Ministerio de Salud de Colombia (CIOMS, 2002; Ministerio de Salud, 1993).

\section{RESULTADOS Y DISCUSIÓN}

El 60,49\% de la población estudiada fueron trabajadores de frigorífico; el 37,04\%, de fincas ganaderas de bovinos doble propósito y, el 2,47\%, trabajadores de un expendio de carne.

De acuerdo con la encuesta, en el frigorífico y en las fincas, el $7,07 \%$ y el $4,76 \%$, respectivamente, han tenido síntomas compatibles con brucelosis. En el momento de la toma de la muestra, los participantes refirieron haber tenido en los últimos seis meses fiebre (20\%), dolor articular (10\%), fatiga $(8 \%)$, sudoración $(3 \%)$, cefalea $(15 \%)$, lumbalgia $(15 \%)$ y debilidad física (2\%). A pesar de tener una sintomatología compatible con la enfermedad por Brucella sp., los resultados por laboratorio indicaron que solamente una persona presentó positividad en la prueba confirmatoria (C-ELISA), lo que sugiere que, tanto la impresión clínica como el diagnóstico por el laboratorio, deben ir paralelos y no deben ser alternativos. Adicionalmente, esta sintomatología es compatible con enfermedades, como la malaria, el dengue, la leptospira, con una alta incidencia en la zona de realización del estudio (SIVIGILA, 2014) o con otras enfermedades que hacen parte del grupo del síndrome febril de etiología desconocida, con las que se debe establecer el diagnóstico diferencial (Niehues, 2013).

Además, es importante tener en cuenta que las características clínicas dependen del estado de la enfermedad y de los órganos y sistemas involucrados. Solamente, se detectó una persona positiva, con síntomas que refirió haber tenido brucelosis previamente y haber presentado fiebre, escalofrío, cefalea y dolores articulares, síntomas que conducen a un diagnóstico de síndrome febril agudo inespecífico. De esta manera, diversos estudios encuentran que los pacientes con brucelosis muestran un alto porcentaje de fiebre, escalofrío, artritis y sudoración (Castro et al. 2005).

La prevalencia encontrada por Aricapa et al. (2008), en 676 muestras humanas evaluadas por RB, en Caldas, fue del $0,14 \%$. En el presente estudio y con el mismo método, 12 de 162 sueros fueron positivos, lo que corresponde a 7,41\%, demostrando una mayor prevalencia en Córdoba, tal vez, por la mayor vocación pecuaria, siendo el promedio de tiempo laboral en el sitio de trabajo, de 10 meses (mínimo=2 meses - máximo $=216$ meses) y donde, de acuerdo con datos del registro de vacunación contra fiebre aftosa adelantado por FEDEGAN, en el 2005, se encuentran 2'104.261 cabezas de ganado bovino, lo que representa, aproximadamente, el $8,3 \%$ de la población bovina del país, calculada en 25’245.716 cabezas (Cuenca et al. 2008).

La seroprevalencia de brucelosis con C-ELISA $(0,7 \%)$ corresponde a un trabajador de una finca, dedicado a oficios varios desde hace 96 meses, quien había referido en la encuesta 
haber tenido brucelosis hace tres meses, posiblemente, debido a que los niveles plasmáticos de anticuerpos de tipo IgM pueden permanecer hasta seis meses postinfección (Castro et al. 2005). Esta prevalencia fue cinco veces mayor a la reportada del 0,14\%, en Caldas (Aricapa et al. 2008). En Colombia, no existen reportes sobre la brucelosis en humanos y siguen siendo aislados, tanto en el tiempo como en el espacio, lo que impide tener mayor claridad sobre la magnitud del problema en el país; sin embargo, tener un único caso confirmado indica que la transmisión sigue existiendo y que no se pueden abandonar los programas de educación y de protección, como mecanismo de prevención.

Al comparar los resultados de las tres pruebas de laboratorio, se encontró que la frecuencia de RB fue del 7,4\%; la de ELISA-C, del 0,7\%; la de FPA-1, del 2,8\% y, la del FPA-2, del 15,33\%, como se muestra en la tabla 1 . La diferencia entre las seroprevalencias obtenidas con los dos protocolos diferentes usados para la prueba de FPA, se puede deber a la relación entre el antígeno y los sueros con respecto a su volumen.

Adicionalmente, cuando se compararon las diferentes técnicas diagnósticas RB, C-ELISA, FPA-1 y FPA-2, mediante el valor del coeficiente de Kappa de las distintas relaciones entre ellas, se evidenció que al comparar la prueba de C-ELISA con $\mathrm{RB}$, el valor de Kappa es de 0,14, lo que indica una fuerza de concordancia leve; al comparar C-ELISA con FPA-1, el valor de kappa fue de -0,009, indicando una concordancia muy leve y, C-ELISA con FPA-2, un valor de Kappa de 0,069, también considerado como de concordancia leve (Cerda \& Villarroel, 2008). Estos resultados sugieren que se debe seguir usando C-ELISA como una prueba de confirmación, hasta que la FPA sea adecuadamente estandarizada para el diagnóstico de brucelosis humana. Esto en el caso en que no se puedan realizar pruebas de laboratorio de detección directa de la bacteria, tales como la "Reacción en Cadena de la Polimerasa" o el hemocultivo (Cevallos et al. 2010; Franco et al. 2007).
De los 98 trabajadores que respondieron la encuesta en el frigorífico, el 51,02\% conoce, por lo menos, un aspecto, un síntoma, una secuela o una forma de transmisión de la enfermedad en los seres humanos, lo que permite inferir que, en general, no existe un conocimiento generalizado del problema que significa la brucelosis para la vida de las personas que están en algún grado de riesgo de contraer la enfermedad.

Algo similar ocurre cuando los encuestados son los trabajadores de las fincas, donde el $46,67 \%$ respondieron conocer alguna de las características de la enfermedad. Cabe anotar que en el frigorífico en donde se realizó parte del trabajo, es una empresa que exporta y, por lo tanto, ha establecido procesos de calidad estandarizados internacionalmente, así como programas de salud ocupacional. Esto se ve reflejado en el hecho de que las actitudes y las prácticas de prevención de la enfermedad son mayores en este grupo de trabajadores que en los de las fincas, $84,85 \%$ y $58,59 \%$, para las actitudes, respectivamente y, $78,12 \%$ y $58,73 \%$, para las prácticas.

Con respecto a las actitudes y las prácticas, tanto en el frigorífico como en las fincas, un porcentaje mayor de trabajadores realiza alguna práctica para prevenir la enfermedad, desde el punto de vista de su alcance y conocimiento. Aparece aquí una controversia, con respecto a la diferencia entre quienes conocen la enfermedad y quienes dicen realizar alguna práctica de prevención; es posible que estas conductas sean por imitación, cumplimiento de normas del lugar de trabajo o porque las observan por temor a adquirir cualquier enfermedad, sin pensar en la brucelosis en particular.

Solamente, una muestra fue positiva para brucelosis; se trata de un trabajador de una finca que fue positivo por los tres métodos RB, C-ELISA y FPA-2; este hecho, tal vez, sea el reflejo de la situación descrita: más personas en el frigorífico tienen conocimientos y observan actitudes y prácticas que quienes laboran en las fincas.

Tabla 1. Distribución de la frecuencia en las diferentes pruebas diagnósticas implementadas en el diagnóstico de brucelosis, en la población a riesgo.

\begin{tabular}{|l|c|c|c|c|}
\hline \multirow{2}{*}{ TÉCNICA } & \multicolumn{2}{|l|}{ POSITIVO } & \multicolumn{2}{l|}{ NEGATIVO } \\
\cline { 2 - 5 } & Frecuencia & $\%$ & Frecuencia & $\%$ \\
\hline RB. $(n=162)$ & 12 & 7,41 & 150 & 92,59 \\
\hline $\begin{array}{l}\text { C-ELISA } \\
(n=145)\end{array}$ & 1 & 0,69 & 144 & 99,31 \\
\hline FPA-1 $(n=143)$ & 4 & 2,8 & 139 & 97,2 \\
\hline FPA-2 $(n=150)$ & 23 & 15,33 & 127 & 84,67 \\
\hline
\end{tabular}


De acuerdo con la Ley 100 del 23 de diciembre de 1993, en Colombia, todas las empresas deben tener afiliados a sus trabajadores en programas de salud ocupacional y afiliados a una Aseguradora de Riesgos Laborales (ARL). El 90\% de los voluntarios refieren estar afiliados a alguna ARL y, el 96\% de los mismos, señalan que en sus lugares de trabajo tienen un programa de salud ocupacional. Por otro lado, el control de la brucelosis implica planeación desde el nivel nacional, mejor cooperación entre los sectores pecuarios y las entidades de salud pública y educación para los profesionales de la salud humana, los veterinarios y la población en general (Obradović \& Velić, 2010).

Los programas de control y de erradicación de la brucelosis bovina tienen un marcado efecto en la incidencia de la infección humana. En Dinamarca, en la década de los años 30, se notificaban unos 500 casos cada año y se logró la erradicación de la enfermedad en humanos, hasta 1962, como consecuencia del tratamiento en los animales (Godfroid et al. 2010). En China, se estableció que el riesgo de contaminación de la leche cruda se reduce adoptando controles, como mantener una tasa de abortos baja y evitar la cría de diferentes tipos de rumiantes en el mismo hato (Ning et al. 2013).

De acuerdo con lo expuesto, se puede concluir que en la población de trabajadores del frigorífico y ordeñadores en el municipio de Montería, existe una baja seroprevalencia de anticuerpos para $B$. abortus, detectado por las técnicas convencionales de RB y C-ELISA, que siguen siendo las pruebas de oro para el diagnóstico de brucelosis en humanos por el laboratorio clínico; sin embargo, es importante anotar que el resultado de la prueba debe ir acompañado de un buena evaluación clínica, para poder determinar un diagnóstico de brucelosis. Es importante tener en cuenta que se hace necesario ajustar los protocolos, utilizando un mayor número de muestras y controles de la misma población, para de esta manera, contribuir a la implementación y validación de los mismos.

El 75\% de los trabajadores del frigorífico y ordeñadores involucrados en este estudio conocen la enfermedad y su sintomatología y asumen conductas para prevenir su contagio. Los particpantes refirieron utilizar guantes de malla de acero, guantes de látex, botas, casco, tapa bocas, gafas protectoras, peto impermeable y overol, con el fin de protegerse de diferentes infecciones.

El desarrollo de políticas de control de enfermedades zoonóticas es un gran reto, primero, por la compleja dinámica de distribución que exhiben estas enfermedades y, segundo, por la necesidad de implementar complejos protocolos para la vigilancia de varias especies animales, incluidos los humanos y esfuerzos de control, utilizando recursos limitados.
Los autores recomiendan diseñar e implementar estudios enfocados en el diagnóstico de brucelosis en Instituciones de Salud de la región, con el fin de conocer toda su epidemiología (focos de transmisión, posibles factores predisponentes, entre otros), así como realizar estudios de prevalencia con un tamaño de muestra mayor, que permitan evaluar la real magnitud del problema y un estudio de metodología, enfocado a estandarizar la técnica de polarización de la fluorescencia con controles propios de la región y compararlo con las técnicas de diagnóstico tradicionales.

Promover actividades conjuntas entre autoridades sanitarias humanas y pecuarias, con el propósito de unificar criterios de acción para la formulación de programas y de proyectos con profesionales, técnicos y población general, enfocados en el cambio de actitudes, así como concientizar a los empleadores de los frigoríficos y de las fincas de hacer una evaluación médica y de laboratorio en humanos, dirigida al diagnóstico de $B$. abortus, por lo menos una vez al año, con el fin de monitorear y evitar brotes de brucelosis.

Agradecimientos. Los autores agradecemos a las directivas y al departamento de salud ocupacional del frigorífico y a los diferentes propietarios y administradores de las fincas, sin cuya colaboración no habría sido posible realizar este estudio. Conflicto de intereses: El manuscrito fue preparado y revisado con la participación de todos los autores, quienes declaramos que no existe conflicto de intereses, que ponga en riesgo la validez de los resultados presentados.

\section{BIBLIOGRAFÍA}

1. ARICAPA, H.J.; JARAMILLO, A.; PÉREZ, J.E.; LONDOÑO, L.; CASTRILLÓN, A.; AMAYA, C.; MURILLO, J.; LARGO, J.; ALZATE, E.; BUITRAGO, F.; FERIS, J.; GALLEGO, M.; HURTADO, J.; OROZCO, J.; HERNÁNDEZ, J.; MARTÍNEZ, A.; SÁNCHEZ, F. 2008. Prevalencia de brucelosis bovina, equina y humana en Caldas, Colombia. Suramérica. Biosalud. 7:7587.

2. CASTRO, H.; GONZÁLEZ, S.; PRATT, M. 2005. Brucelosis: una revisión práctica. Acta Bioquim Clin Latinoam. 39(2):203-216.

3. CIOCHINI, A.; SERANTES, D.; MELLI, L.; IWASHKIW, J.; DEODATO, B.; WALACH, J.; FELDMAN, N.; UGALDE, J.; COMERCI, D. 2013. Development and Validation of a Novel Diagnostic Test for Human Brucellosis Using a Glyco-engineered Antigen Coupled to Magnetic Beads. PloS Negl Trop Dis 7(2): e2048. doi:10.1371/journal.pntd.0002048. Disponible desde Internet en http://www.ncbi.nlm.nih.gov/pmc/?t 
erm $=$ Blood + culture + for + Brucellosis + diagnose (con acceso 29/06/14).

4. CLAVIJO, E.; DÍAZ, R.; ANGUITA, A.; GARCÍA, A.; PINEDO, A.; SMIT, H. 2003. Comparison of a dipstick assay for detection of Brucella-specific immunoglobulin $M$ antibodies with other tests for serodiagnosis of human brucellosis. Clin. Diagn. Lab. Immunol. 10(4):612-615.

5. CERDA, J.; VILLARROEL, L. 2008. Evaluación de la concordancia inter-observador en investigación pediátrica: Coeficiente de Kappa. Rev. Chil. Pediatr. 79(1):54-58.

6. CEVALLOS, O.; CARRANZA, M.; SAUCEDO, S.; ROMERO, D.; RAMOS, L.; REYES, X.; COBEÑA, K.; RODRÍGUEZ, A.; MARISCAL, J.; MESTANZA, C.; CADME, M.; ESCOBAR, A.; VERA, J.; CANCHIGNIA, F. 2010. Diagnóstico serológico (Rosa de Bengala) y molecular (PCR) de Brucelosis en humano. Ciencia y Tecnología 3(1):27-32.

7. CONSEJO DE ORGANIZACIONES INTERNACIONALES DE LAS CIENCIAS MÉDICAS -CIOMS-. 2002. Pautas éticas internacionales para la investigación y la experimentación biomédica en seres humanos. Ginebra. Disponible desde Internet en: http://www.ub.edu/rceue/archivos/Pautas_Eticas_Internac.pdf (con acceso 25/06/14).

8. CUENCA, N.; CHAVARRO, F.; DÍAZ, O. 2008. El sector de ganadería bovina en Colombia. Aplicación de modelos de series de tiempo al inventario ganadero. Rev Fac. Cienc. Econ. 16(1):165-177.

9. DEAN, A.; CRUMP, L.; GRETER, H.; HATTENDROF, J.; SCHELLING, E.; ZINSSTAG, J. 2012. Clinical Manifestations of Human Brucellosis: A Systematic Review and Meta-Analysis. PloS Negl Trop Dis 6(12):e1929. doi:101371/journal.pntd.0001929.

10. DÍAZ, R.; CASANOVA, A.; ARIZA, J.; MORIYÓN, I. 2011. The Rose Bengal Test in Human brucellosis: A Neglected Test for the Diagnosis of a Neglected Disease. PloS Negl Trop Dis 5(4): e950.doi:10.1371/ journal.pntd.0000950. Disponible desde Internet en http://www.ncbi.nlm.nih.gov/pmc/?term=The +Ros e+Bengal+Test +in +Human+Brucellosis\%3A+A+ Neglected + Test + for + the + Diagnosis + of $+\mathrm{a}+\mathrm{Negl}$ ected+Disease (con acceso 15/06/14).

11. FERNÁNDEZ, E.; GÓMEZ, F. 2009. Brucelosis. Rev. Méd. Costa Rica y Centroamérica. 67(590):399-404.
12. FRANCO, M.; MULDER, M.; GILMAN, R.; SMITS, H. 2007. Human brucellosis. Lancet Infect Dis. 7:775786.

13. GODFROID, J.; NIELSEN, K; SAEGERMAN, C. 2010. Diagnosis of Brucellosis in Livestock and Wildlife. CMJ. 296-305 doi: 10.3325/cmj.2010.51.296.

14. HALLING, S.; PETERSON, B.; BRICKER, B.; ZUERNER, R.; QING, Z.; KAPUR, V.; ALT, D; OLSEN, S. 2005. Completion of the genome sequence of Brucella abortus and comparison to the highly similar genomes of Brucella melitensis and Brucella suis. J. Bacteriol. 187(8):2715-2726.

15. LUCERO, N.E.; ESCOBAR, G.I.; AYALA, S.M.; HASAN, D. 2008. Manual de Procedimientos: Técnicas para el Diagnóstico de Brucelosis Humana. WHO Global Salm Surv. 78p.

16. MINISTERIO DE SALUD, REPÚBLICA DE COLOMBIA. Resolución 08430 de 1993. Por la cual se establecen las normas científicas, técnicas y administrativas para la investigación en salud. Disponible desde Internet en: http://www.unisabana.edu.co/ fileadmin/Documentos/Investigacion/comite_de_etica/Res_8430_1993_-_Salud.pdf (con acceso el 08/05/14).

17. MITKA, S.; ANETAKIS, C.; SOULIOU, E.; DIZA, E.; KANSOUZIDOU, A. 2007. Evaluation of different PCR assays for early detection of acute and relapsing brucellosis in humans and comparison with conventional methods. J. Clin. Microbiol. 45(4):1211-1218.

18. MORALES, D.; COMBARIZA, D. 2004. Seroprevalencia de brucelosis en trabajadores de mataderos de municipios del Tolima, Colombia. Rev. Cienc. Salud. 2(1):15-23.

19. NIELSEN, K.; GALL, D.; JOLLEY, M.; LEISHMAN, G.; BALSEVICIUS, S.; SMITH, P.; NICOLETTI, P.; THOMAS, F. 1996. A homogeneous fluorescence polarization assayfor detection of antibodie to Brucella abortus. J. Immunol. Methods. 195(1-2):161-168.

20. NIELSEN, K.; SMITH, P.; WIDDISON, J.; GALL, D.; KELLY, L.; KELLY, W.; NICOLETTI, P. 2004. Serological discrimination by indirect enzime immunoassay between the antibody response to Brucella sp. and Yersinia enterocolitica 0:9 in cattle and pigs. Vet. Microbiol. 100(1-2):25-30. 
21. NIELSEN, K.; YU, W. 2010. Serological diagnosis of brucellosis. Contributions, Sec. Biol. Med. Sci. MASA. 31(1):65-89.

22. NIEHUES, T. 2013. The Febrile Child: Diagnosis and treatment. Deutsch. Ärtzebl. Int 110(45):764-774.

23. NING, P.; GUO, M.; GUO, K.; XU, L.; REN, M.; CHENG, Y.; ZHANG, Y. 2013. Identification and effect decomposition of risk factors for brucella contamination of raw whole milk in China. PLoS ONE 8(7):e68230. doi:10.1371/journal.pone.0068230.

24. NÖKLER, K.; MAVES, R.; CEPEDA, D.; DRAEGER, A.; MAYER-SCHOLL, A.; CHACALTANA, J.; CASTAÑEDA, M.; ESPINOSA, B., CASTILLO, R.; HALL, E.; AL DAHOUK, S.; GILMAN, R.; CABEZA, F.; SMITS, H. 2009. Molecular epidemiology of brucella genotypes in patients in a Major Hospital in central Peru. J. Clin. Microbiol. 47(10):3147-3155.

25. OBRADOVIĆ, Z.; VELIĆ, R. 2010. Epidemiological characteristics of brucellosis in Federation of Bosnia and Hersegovina. Croat. Med. J. 51:345-350.

26. OLIVERA, M.; RISTOW, P.; KO, A.; Di-LORENZO, C. 2013. Serological trail of Brucella infection in an urban slum population in Brazil. J Infect Dev.Ctries.; 6(9): 675-679.

27. ORGANIZACIÓN MUNDIAL DE SANIDAD ANIMAL OIE-. 2008. Brucelosis bovina Capítulo 2.4.3. Disponible desde Internet en: http://web.oie.int/esp/normes/mmanual/pdf es_2008/2.04.03.\%20Brucelosis \%20bovina.pdf (con acceso el 08/05/14).

28. PAPPAS, G.; AKRITIDIS, N.; BOSILKOVSKI, M.; TSIANOS, E. 2005. Brucellosis. N. Engl. J. Med. 352:2325-2336.

29. PULIDO, I.; MANDIUS, R.; RIVERO, T.; DUARTE, O. 2002. Atlas de los sistemas de producción bovina. Módulo región Caribe. Plan de modernización tecnológica de la ganadería bovina colombiana. Bogotá (Colombia). Corpoica. 73p.

31. ROJAS, X.; MUÑOZ, S.; OTTO, B.; PÉREZ, B.; NIELSEN, K. 2004. Utilización de los test de fluorescencia polarizada (FP) y Elisa de Competencia (C-Elisa) en el diagnóstico de brucelosis de camélidos. Arch. Med. Vet. 36(1):59-64.

31. SISTEMA DE VIGILANCIA EN SALUD PÚBLICA -SIVIGILA-. Boletín epidemiológico semanal. Semana epidemiológica 37 de 2014

32. WELLINGHAUSEN, N.; NÖCKLER, K.; SIGGE, A.; BARTEL, M.; ESSIG, A.; POPPERT, S. 2006. Rapid detection of Brucella spp. In blood cultures by fluorescence in situ hybridization. J. Clin. Microbiol. 44(5):1828-1830.

Recibido: Mayo 28 de 2014

Aceptado: Octubre 20 de 2014

\section{Como citar:}

Quintero, G.; Calderón, A.; Rodríguez, V.; Barrios, C.; Yasnot, M.F.; Villadiego, M. 2014. Determinación de la seroprevalencia de anticuerpos para Brucella abortus. en trabajadores de un frigorífico y ordeñadores en Montería, Córdoba (Colombia). Rev. U.D.C.A Act. \& Div. Cient. 17(2): 333-340. 